\title{
Effects of Altered Brain Noradrenaline Level on Acute Stress Pathology in Rats
}

\author{
GARY B. GLAVIN*, MASATOSHI TANAKA, AKIRA TSUDA, \\ YASUKO KOHNO, YOSHIO HOAKI \\ AND NOBUYUKI NAGASAKI \\ *Department of Psychology, University of Winnipeg, Manitoba, Canada R3B 2E9 \\ and Department of Pharmacology, Kurume University School of Medicine, \\ Kurume, 830 Japan
}

Received for publication April 7, 1983

\begin{abstract}
Summary: The present study sought to examine pre-stress manipulations designed to alter brain NA levels in animals prior to their being exposed to the acute stressor of supine restraint-cold. Forty rats were divided into five equal groups which were given either no pre-treatment (control); a brief swim; a 1 $\mathrm{hr}$. period of random, inescapable footshock; a $1 \mathrm{hr}$. period of footshock preceded by desipramine $\mathrm{HCl}$ administration; or a single injection of methamphetamine $\mathrm{HCl}$. Following $3 \mathrm{hrs}$. of supine restraint-cold, all rats were decapitated and their brains removed and analyzed fluorometrically for NA, DA and MHPG$\mathrm{SO}_{4}$. Stomach, thymus, spleen and adrenals were also dissected and examined. Trunk blood was also assayed for plasma corticosterone. Results showed that cold swim pre-treatment produced significantly decreased NA level and significantly elevated MHPG-SO $\mathrm{SO}_{4}$ level, indicative of greater NA turnover. These animals also displayed the greatest extent of gastric damage. Desipramine attenuated the effects of inescapable shock exposure and along with the methamphetamine-treated animals, displayed less gastrointestinal ulcers. A modest relationship was observed between NA level and ulcer frequency. It is suggested that brain NA level prior to exposure to an acutely stressful situation is an important determinant of the severity of the pathophysiological response of an organism to that situation.
\end{abstract}

Key words: supine restraint-cold stress - footshock - cold swimm - desipramine - methamphetamine - noradrenaline - $\mathrm{MHPG}-\mathrm{SO}_{4}$ - gastric ulcers

\section{Introduction}

Of the functionally important brain monoamine neurotransmitters, noradrenaline (NA) has received a significant amount of research attention in recent years. Various forms of physical and psychological stress appear to influence brain NA activity. In general, it appears that acute (relatively short duration) stressors produce decreased NA level and increased NA turnover, as measured by levels of 3-methoxy-4-hydroxyphenylethyleneglycol sulfate (MHPG-SO ${ }_{4}$ ) (Schanberg et al. 1968). The functional

Reprint requests to: Gary B. Glavin, Ph. D., Department of Psychology, University of Winnipeg, 515 Portage Avenue, Winnipeg, Manitoba, Canada, R3B 2E9. Supported by N.S. E. R. C. A8072 and by the Matsumae International Foundation grants to the first author. 
significance of such altered brain NA activity has been linked to depressive disorders in the "biogenic amine" theory of affective disorders (Schildkraut and Kety, 1967), and more recently by Anisman and Zacharko (1982) and by Weiss et al. (1979; 1981). These authors suggest that stressinduced decreases in NA levels are associated with impaired coping ability, impaired perceived effectiveness of coping behavior, anhedonia and, ultimately, behavioral depression. The purpose of the present study was to alter brain NA activity in a known fashion prior to exposure to an acutely stressful situation and to examine the neurochemical and pathological sequelae prestress increases or decreases in brain NA activity.

\section{Methods}

\section{Subjects}

Subjects were forty male Wistar rats weighing approximately 200 ( \pm 10 ) grams at the start of the experiment.

\section{Procedure}

Rats were randomly assigned to five groups ( $\mathrm{n}=8$ per group). All rats were starved for $12 \mathrm{hrs}$. prior to beginning the experiment. Rats in one group were then individually given a 5 minute cold swim $\left(10{ }^{\circ} \mathrm{C}\right)$, allowed a 30 minute rest period in their home cage, and then subjected to 3 hours of restraint in the supine position in a cold $\left(4{ }^{\circ} \mathrm{C}-6{ }^{\circ} \mathrm{C}\right)$ environment (Glavin, 1980). Cold swim has been shown to markedly decrease brain NA level (Weiss et al. 1981). Animals in a second group were exposed to unpredictable, inescapable foot shock $(2.5 \mathrm{~mA}$ for $0.5 \mathrm{sec}$ for 60 minutes VI 5 min. ) prior to supine restraint-cold. This shock procedure has also been shown to deplete brain NA (Anisman et al. 1980). A third group of rats received the same inescapable, unpredictable shock regimen, but were first given a single i. p. injection of the NA reuptake inhibitor, desipramine hydrochloride, $10 \mathrm{mg} / \mathrm{kg}$. They were then given the supine restraint-cold treatment as with the first two groups. Desipramine has been shown to attenuate the NA-reducing effects of inescapable shock exposure (Anisman et al. 1980; Weiss et al. 1981). Animals in a fourth group received a single s.c. in jection of methamphetamine hydrochloride, $3 \mathrm{mg} / \mathrm{kg}$, prior to supine restraint-cold exposure. Methamphetamine stimulates locus coeruleus, NA cell body site, and potentiates NA release (Toshima, 1979). A fifth group of rats remained untreated prior to exposure to the supine restraint-cold regimen.

Following restraint, all rats were decapitated and the brains rapidly removed. The pineal body, cerebellum, and spinal cord below the pyramids were quickly dissected over dry ice and discarded. Blood from the cervical wound was collected into heparinized tubes. Separated plasma and brains were stored at $-45{ }^{\circ} \mathrm{C}$ until assayed. The stomach, duodenum, adrenal glands, spleen and thymus were removed, cleaned, weighed and examined macroscopically for pathological signs. In the case of the stom achs, the incidence and frequency of any observed erosions and/or ulcers were recorded. Plasma corticosterone levels were determined by a slight modification of the method of van der Vies (1961). NA, dopamine (DA), and MHPG-SO levels were determined fluorometrically according to the method of Kohno et al. (1979).

\section{Results}

The brain assay data for the five groups are shown in Table 1. Plasma corticosterone, organ weight, and ulcer data are shown in Table 2. Analysis of variance indicated that significant differences among treatment groups occurred in NA level $\{\mathrm{F}(4,35)=2$. 89; $\mathrm{p}<0.05\rfloor ; \mathrm{MHPG}-\mathrm{SO}_{4}$ level $\{\mathrm{F}(4,35)=4.79$; $\mathrm{p}<0.001]$; ulcer frequency $[\mathrm{F}(4,35)=7.28$; 
TABLE 1

Summary of Brain Assay Data for the Restraint-Pre-

Treatment Study (Mean \pm S. E.M.)

\begin{tabular}{llcr}
\hline \multicolumn{1}{c}{ Group } & NA (ng/g) & MHPG-SO $_{4}(\mathrm{ng} / \mathrm{g})$ & $\mathrm{DA}(\mathrm{ng} / \mathrm{g})$ \\
\hline cold swim & $301.4(19.5)$ & $259.6(9.5)$ & $1080.7(101.9)$ \\
shock only & $347.6(9.1)$ & $233.2(10.4)$ & $923.1(27.2)$ \\
shock + desipramine & $388.6(23.8)$ & $191.5(15.1)$ & $987.6(28.7)$ \\
methamphetamine & $356.5(22.6)$ & $184.9(11.2)$ & $1084.5(64.4)$ \\
$\begin{array}{l}\text { no pre-treatment } \\
\text { control }\end{array}$ & $321.9(12.5)$ & $209.8(18.6)$ & $934.2(18.5)$ \\
\hline
\end{tabular}

TABLE 2

Summary of Ulcer, Organ and Plasma Corticosterone Data for the Restraint-Pre-Treatment Study (Mean \pm S. E.M.)

\begin{tabular}{lcccccc}
\hline \multicolumn{1}{c}{ Group } & $\begin{array}{l}\text { Number of } \\
\text { Ulcers }\end{array}$ & $\begin{array}{l}\text { Ulcer } \\
\text { Incidence }\end{array}$ & $\begin{array}{l}\text { Adrenal } \\
\text { Weight(mg) }\end{array}$ & $\begin{array}{l}\text { Spleen } \\
\text { Weight(g) }\end{array}$ & $\begin{array}{l}\text { Thymus } \\
\text { Weight(g) }\end{array}$ & $\begin{array}{l}\text { Plasma } \\
\text { Corticosterone } \\
(\mu \mathrm{g} / \mathrm{dl})\end{array}$ \\
\hline $\begin{array}{l}\text { cold swim } \\
\text { shock only }\end{array}$ & $19.8(3.3)$ & $8 / 8$ & $45.9(1.4)$ & $0.627(0.04)$ & $0.601(0.03)$ & $39.75(3.87)$ \\
$\begin{array}{l}\text { shock }+ \\
\text { desipramine }\end{array}$ & $14.6(4.0)$ & $8 / 8$ & $43.5(2.4)$ & $0.565(0.04)$ & $0.608(0.04)$ & $41.56(9.08)$ \\
$\begin{array}{l}\text { methamphetamine } \\
\text { no pre-treatment } \\
\text { control }\end{array}$ & $4.6(1.2)$ & $6 / 8$ & $41.6(2.7)$ & $0.618(0.02)$ & $0.613(0.02)$ & $38.50(5.58)$ \\
\hline
\end{tabular}

$\mathrm{p}<0.001]$ and plasma corticosterone level $\lceil\mathrm{F}(4,35)=4.08 ; \mathrm{p}<0.01]$. Tukey multiple comparison tests revealed that for NA level, shock + desipramine and methamphetaminetreated groups had significantly higher NA levels than did controls, while cold swimtreated rats displayed significantly lower NA levels, relative to non-pre-treated controls. For MHPG-SO ${ }_{4}$ level, cold swimtreated rats displayed significantly higher levels relative to controls. Significantly greater gastric ulceration was observed in cold-swim and shock-treated rats relative to controls, while methamphetamine and shock + desipramine-treated rats displayed significantly fewer ulcers than did controls. Plasma corticosterone data were inconsistent, but cold-swim and shock-treated rats showed significant elevations relative to the shock + desipramine and methamphetamine-treated groups.

\section{Discussion}

Cold swim pretreatment resulted in the lowest NA level, the highest $\mathrm{MHPG}-\mathrm{SO}_{4}$ level and the greatest amount of gastric ulcer of any other treatment. Cold swim and shock only animals displayed heavier adrenal weights and lighter thymus weights than did control animals. This pattern of organ changes is consistent with the classic pattern of stress pathology outlined by other researchers (Glavin, 1980). Shock+desipramine and methamphetamine-treated rats displayed lighter adrenal glands and somewhat lighter thymus glands than did control rats; suggesting a slight attenuation of stress pathology in these groups. No organ weight differences between groups, however, were statistically significant.

Inescapable shock exposure resulted in the next largest effect on brain NA turn- 
over and gastric ulcer production. In contrast, methamphetaime pretreated rats and rats given inescapable shock plus desipramine displayed elevated NA levels, lower MHPG-SO ${ }_{4}$ levels and much less gastric ulceration than the former groups. It appears that treatments which augment rapid NA turnover, wherein utilization rate exceeds synthesis, are associated with greater acute stress-induced pathological changes than are treatments which result in enhanced NA production. Recently, Anisman and Zacharko (1982) and Weiss et al. (1981) have formulated a hypothesis concerning the role of environmental stress in behavioral depression:

environmental stressor $\rightarrow$ neurochemical change (decreased NA?) $\rightarrow$ altered (impaired?) coping ability $\rightarrow$ behavioral depression

According to these researchers, some environmental stressors in and of themselves can produce markedly altered brain monoamine activity which in turn decreases either the extent of or the perceived effectiveness of an organism's coping behavior, one consequence of which is behavioral depression. The present data suggest that an organism which enters an acutely stressful situation already depleted of brain NA will have greater pathological consequences from that stressor than will an organism which is either not depleted or which has enhanced brain NA activity. Current research is underway examining the regional brain NA and MHPG-SO $\mathrm{SO}_{4}$ responses to this paradigm.

Acknowledgement: We are grateful to Miss. S. Takeda and Mrs. M. Kato for expert technical assistance. We also thank Nippon Roche K. $\mathrm{K}$. for a generous gift of MHPG-SO 4 and Dainippon Co. Ltd. for methamphetamine $\mathrm{HCl}$.

\section{References}

Anisman, H. and $Z_{\text {Acharko, R. (1982). Depres- }}$ sion: The predisposing effects of stress. The Behav. and Brain Sci. 5, 89-137.

Anisman, H., Pizzino, A. and Sklar, L. (1980). Coping with stress: Norepinephrine depletion and escape performance. Brain Res. 191, 583588.

Glavin, G. (1980). Restraint ulcer: History, current research and future implications. Brain Res. Bull. 5, 51-58.

Kohno, Y., Matsuo, K., Tanaka, M., Furukawa, T. and NAGASAKI, N. (1979). Simultaneous determination of noradrenaline and 3-methoxy 4 -hydroxyphenylethyleneglycol sulfate in discrete brain regions of the rat. Anal. Biochem. 97, 352-358.

Schanberg, S., Schildkraut, J., Breese, G. and KopIN, I. (1968). Metabolism of norepinephrine$\mathrm{H}^{3}$ in rat brain-identification of conjugated 3-methoxy-4-hydroxyphenylglycol as the major metabolite. Biochem. Pharmacol. 17, 247254.

Schildkraut, J. and Kety, S. (1967). Biogenic amines and emotion. Science, 156, 21-30.

Toshima, N. (1979). Changes in behavior and brain noradrenergic neurons by chronic treatment with methamphetamine in the rat. J. Kurume. Med. Assoc. 42, 1283-1297.

van der VIEs, J. (1961). Individual determination of cortisol and corticosterone in a single sample of peripheral blood. Acta Endoc. 38, 399406.

Weiss, J., Glazer, H., Pohorecky, L., Bailey, W. and Schneider, L. (1979). Coping behavior and stress-induced behavioral depression: Studies of the role of brain catecholamines. In: The Psychobiology of Depressive Disorders: Implications for the effects of stress. ed. R. Depue., 125-160, New York: Academic Press.

Weiss, J., Goodman, P., Losito, B., Corrigan, S., Charry, J. and Bailey, W. (1981). Behavioral depression produced by an uncontrollable stressor: Relationship to norepinephrine, dopamine and serotonin levels in various regions of rat brain. Brain Res. Rev. 3, 167-205. 